\title{
On the Stability of Immunoreactive Glucagon in Plasma Samples
}

\author{
T. Hendriks and T. J. Benraad \\ Department of Experimental and Chemical Endocrinology, University of Nijmegen, Nijmegen, The Netherlands
}

Summary. The stability of glucagon immunoreactivity in plasma samples, as measured with antiserum $30 \mathrm{~K}$, has been investigated. Post-prandial blood samples were collected and processed both with added Trasylol at $4{ }^{\circ} \mathrm{C}$ and without Trasylol at room temperature. Incubation at room temperature for up to $7 \mathrm{~h}$ without added Trasylol did not result in significant loss of $30 \mathrm{~K}$-immunoreactive glucagon. Blood samples both from non-diabetic and diabetic persons could be collected and centrifuged at room temperature and stored at $-20^{\circ} \mathrm{C}$ without Trasylol for more than 2 months without loss of $30 \mathrm{~K}$ immunoreactivity, as compared to Trasylol-containing controls kept at $4{ }^{\circ} \mathrm{C}$ during handling. The distribution of $30 \mathrm{~K}$-immunoreactive glucagon over the various components, obtained after chromatography of plasma on Ultrogel AcA54, was not significantly altered when blood samples, both from normal persons and from patients with chronic renal failure, were processed at room temperature and subsequently stored at $-20^{\circ} \mathrm{C}$ without addition of Trasylol. Our results indicate that collection and centrifugation of blood at room temperature without the addition of a proteinase inhibitor and subsequent storage at $-20^{\circ} \mathrm{C}$ does not result in loss of $30 \mathrm{~K}$ immunoreactive glucagon.

Key words: Pancreatic glucagon, immunoreactive glucagon, radioimmunoassay, protease inhibitor, Trasylol, antiserum $30 \mathrm{~K}$.

Blood samples which are to be used for the radioimmunoassay of pancreatic glucagon are generally handled with special care because of the assumption that this hormone is very sensitive to proteolytic degradation. Samples are collected in precooled tubes which contain a proteinase inhibitor, Trasylol [1] or benzamidine [2], and kept on ice followed by rapid centrifugation at $4{ }^{\circ} \mathrm{C}$ and subsequent storage of the plasma at $-20^{\circ} \mathrm{C}$.

There is little doubt about the damaging effects of human plasma on iodinated glucagon [1-4]. However, the susceptibility of endogenous glucagon to enzymatic degradation has been poorly documented. Heding [5] and Nonaka and Foa [6] have described a significant loss of plasma immunoreactive glucagon (IRG) when blood samples were not treated with a proteinase inhibitor. In contrast, Eisentraut et al. [1] and Hazzard et al. [4] reported that addition of Trasylol to the blood samples had no effect upon the level of plasma glucagon ultimately measured by radioimmunoassay. If indeed endogenous IRG is less sensitive to proteolytic attack than is generally taken for granted, the processing of blood samples might be considerably simplified. We have therefore investigated the stability of IRG, as measured with Unger's antiserum $30 \mathrm{~K}$, in blood samples.

\section{Materials and Methods}

\section{Collection and Processing of Blood Samples}

Blood samples were collected from patients in the post-prandial state visiting the outpatient clinic of the Department of Internal Medicine. Depending on the type of experiment (see text) blood samples were either placed in chilled tubes containing heparin and $500 \mathrm{U}$ Trasylol per $\mathrm{ml}$ blood or in tubes kept at room temperature and containing buffer $(0.2 \mathrm{~mol} / 1$ glycine, $2.5 \mathrm{~g} / 1$ human serum albumin, $\mathrm{pH} 8.8$ ) instead of Trasylol. Trasylol containing samples were maintained and centrifuged $(10 \mathrm{~min}$ at $5000 \times \mathrm{g})$ at $4{ }^{\circ} \mathrm{C}$, while samples without Trasylol were processed at room temperature. After centrifugation plasma was separated and stored at $-20^{\circ} \mathrm{C}$. Immediately before assay the samples were thawed and recentrifuged at $4{ }^{\circ} \mathrm{C}$ and the supernatants were used for radioimmunoassay or chromatography. 
Table 1. A comparison of IRG levels in plasma from non-diabetic persons, processed with and without added Trasylol. Blood was collected from 10 persons and each sample was divided over four tubes, two with and two without Trasylol. After centrifugation at $4{ }^{\circ} \mathrm{C}$ (Trasylolcontaining tubes) or room temperature (tubes without added Trasylol) samples were stored at $-20^{\circ} \mathrm{C}$ for 2 days or 64 days, respectively. Results are expressed as the average of three determinations plus or minus standard deviation

\begin{tabular}{|c|c|c|c|c|c|c|}
\hline \multirow[t]{2}{*}{ Subject } & \multicolumn{3}{|c|}{ Storage for 2 days } & \multicolumn{3}{|c|}{ Storage for 64 days } \\
\hline & $+\underset{(\mathrm{pg} / \mathrm{ml})}{\text { Trasylol }}$ & $\begin{array}{c}\text { - Trasylol } \\
\text { (pg/ml) }\end{array}$ & $\frac{- \text { Trasylol }}{+ \text { Trasylol }} \times 100 \%$ & $+\underset{(\mathrm{pg} / \mathrm{ml})}{\text { Trasylol }}$ & $\begin{array}{r}- \text { Trasylol } \\
(\mathrm{pg} / \mathrm{ml})\end{array}$ & $\frac{- \text { Trasylol }}{\text { + Trasylol }} \times 100 \%$ \\
\hline 1 & $253 \pm 35$ & $272 \pm 2$ & $108 \pm 15$ & $260 \pm 15$ & $261 \pm 6$ & $100 \pm 6$ \\
\hline 2 & $72 \pm 5$ & $79 \pm 8$ & $110 \pm 13$ & $82 \pm 8$ & $81 \pm 3$ & $99 \pm 10$ \\
\hline 3 & $95 \pm 8$ & $87 \pm 3$ & $92 \pm 8$ & $85 \pm 2$ & $93 \pm 8$ & $109 \pm 10$ \\
\hline 4 & $63 \pm 2$ & $59 \pm 4$ & $94 \pm 7$ & $70 \pm 1$ & $70 \pm 2$ & $100 \pm 3$ \\
\hline 5 & $112 \pm 12$ & $117 \pm 13$ & $104 \pm 16$ & $109 \pm 6$ & $107 \pm 5$ & $98 \pm 7$ \\
\hline 6 & $50 \pm 10$ & $49 \pm 9$ & $98 \pm 27$ & $53 \pm 2$ & $57 \pm 5$ & $108 \pm 10$ \\
\hline 7 & $51 \pm 4$ & $48 \pm 6$ & $94 \pm 14$ & $54 \pm 8$ & $54 \pm 1$ & $100 \pm 15$ \\
\hline 8 & $63 \pm 3$ & $67 \pm 7$ & $106 \pm 12$ & $61 \pm 5$ & $57 \pm 1$ & $93 \pm 8$ \\
\hline 9 & $58 \pm 9$ & $61 \pm 9$ & $105 \pm 23$ & $61 \pm 1$ & $64 \pm 4$ & $105 \pm 7$ \\
\hline \multirow[t]{2}{*}{10} & $124 \pm 7$ & $130 \pm 10$ & $105 \pm 10$ & $123 \pm 4$ & $126 \pm 3$ & $102 \pm 4$ \\
\hline & $94 \pm 61$ & $97 \pm 67$ & & $96 \pm 62$ & $97 \pm 62$ & \\
\hline
\end{tabular}

\section{Gel Chromatography}

Plasma was loaded ( $1800 \mu \mathrm{l}$ in $200 \mu \mathrm{l} 60 \% \mathrm{w} / \mathrm{v}$ saccharose) onto a $1.6 \times 34 \mathrm{~cm}$ Ultrogel AcA54 column. The samples were eluted $\left(12 \mathrm{ml} / \mathrm{h}\right.$ ) at $4{ }^{\circ} \mathrm{C}$ with $0.2 \mathrm{~mol} / 1$ glycine, $\mathrm{pH} 8.8$, containing $2.5 \mathrm{~g} / 1$ human serum albumin and $50 \mathrm{U} / \mathrm{ml}$ Trasylol. Two ml eluates were collected, lyophilised and stored at $-20^{\circ} \mathrm{C}$. Immediately before assay the fractions were reconstituted with $750 \mu$ water.

\section{Radioimmunoassay of Glucagon}

Immunoreactive glucagon in the samples was measured using antiserum 30K, essentially according to Faloona and Unger [7]. The buffer employed for the dilution of antiserum, tracer and standards contained $0.2 \mathrm{~mol} / 1$ glycine, $2.5 \mathrm{~g} / \mathrm{l}$ human serum albumin and $1 \%$ $(\mathrm{v} / \mathrm{v})$ normal sheep plasma, at $\mathrm{pH}$ 8.8. The incubation mixture consisted of $500 \mu \mathrm{l}$ (15 pg) ${ }^{125}$ I-glucagon, $100 \mu \mathrm{l}$ Trasylol $(1000 \mathrm{U}), 200 \mu \mathrm{l}$ sample or standard $(20$ to $1000 \mathrm{pg} / \mathrm{ml})$ and $400 \mu \mathrm{l}$ antiserum $30 \mathrm{~K}$ (dilution 1:17000). After incubation for 4 days at $4{ }^{\circ} \mathrm{C}$, bound and free fractions were separated by means of dextran-coated charcoal. Immediately before the charcoal-dextran mixture $(200 \mu \mathrm{l} \quad 1.25 \% \mathrm{w} / \mathrm{v}$ charcoal, $0.62 \% \mathrm{w} / \mathrm{v}$ dextran in $0.2 \mathrm{~mol} / \mathrm{I}$ glycine, $\mathrm{pH} 8.8$ ), $200 \mu \mathrm{l}$ normal sheep plasma was added to all tubes. After $45 \mathrm{~min}$ at $4{ }^{\circ} \mathrm{C}$ the samples were centrifugated for 10 min at $3000 \times \mathrm{g}$, supernatants were collected by decantation and radioactivity was counted. The detection limit of the assay was $20 \mathrm{pg} / \mathrm{ml}$. Intra- and interassay coefficients of variation were found to be $6 \%(n=10)$ and $13 \%(n=10)$, respectively, using a pool plasma which contained $110 \mathrm{pg} / \mathrm{ml}$ IRG.

\section{Materials}

Antiserum $30 \mathrm{~K}$ was purchased from Prof. R. H. Unger (Dallas, USA), ${ }^{125}$ I-glucagon, $200-300 \mathrm{mCi} / \mathrm{mmol}$ from Novo (Denmark) and crystalline beef-pork glucagon (lot 258-V016-235) was a gift from Eli Lilly Benelux. Human serum albumin was obtained from Behring Institut (Germany), Trasylol from Bayer (Germany), charcoal from Fisher Scientific Company (USA) and dextran T70 and Ultrogel AcA54 from Pharmacia (Sweden). Normal sheep plasma was collected from Texel sheep, Central Animal Laboratory of the Medical Faculty, University of Nijmegen.

All other reagents were of analytical grade.

\section{Results}

\section{K-immunoreactivity in Untreated Plasma}

The stability of the $30 \mathrm{~K}$-immunoreactivity was examined in plasma samples from 10 non-diabetics and 10 diabetics. Identical blood samples were processed under the following two conditions: [1] in the presence of Trasylol and at $4{ }^{\circ} \mathrm{C}$; [2] without added Trasylol and at room temperature.

Table 1 shows that neither after 2 days nor after 64 days storage at $-20{ }^{\circ} \mathrm{C}$ did any of the Trasylolfree non-diabetic plasma show a significant loss of IRG as compared to its Trasylol-containing counterpart. The results in the diabetic group (Table 2) were similar, although not as unequivocal. However, none of the plasma samples showed a consistent decline in IRG upon storage without Trasylol. Thus Trasylolfree plasma does not lose $30 \mathrm{~K}$-immunoreactivity when stored at $-20^{\circ} \mathrm{C}$ for up to 74 days. An additional experiment showed the immunoreactivity to remain stable for as much as 109 days. So far, we have not investigated storage for a more prolonged time period.

In the experiments represented in Tables 1 and 2 blood was processed as quickly as possible before plasma was stored at $-20^{\circ} \mathrm{C}$. However, in an initial experiment it was established that blood can be left at room temperature for up to 7 hours without loss of $30 \mathrm{~K}$-immunoreactivity. Plasma was collected with or 
Table 2. A comparison of IRG levels in plasmas from diabetic persons, processed with and without added Trasylol. Blood was collected from 10 persons and each sample was divided over four tubes, two with and two without Trasylol. After centrifugation at $4{ }^{\circ} \mathrm{C}(\mathrm{Trasylol}-$ containing tubes) or room temperature (tubes without added Trasylol) samples were stored at $-20^{\circ} \mathrm{C}$ for 2 or 74 days, respectively. Results are expressed as the average of three determinations plus or minus standard deviation

\begin{tabular}{|c|c|c|c|c|c|c|}
\hline \multirow[t]{2}{*}{ Subject } & \multicolumn{3}{|c|}{ Storage for 2 days } & \multicolumn{3}{|c|}{ Storage for 74 days } \\
\hline & $+\underset{(\mathrm{pg} / \mathrm{ml})}{\text { Trasylol }}$ & $\begin{array}{r}\text { - Trasylol } \\
\text { (pg/ml) }\end{array}$ & $\frac{- \text { Trasylol }}{+ \text { Trasylol }} \times 100 \%$ & $+\underset{(\mathrm{pg} / \mathrm{ml})}{\text { Trasylol }}$ & $-\underset{(\mathrm{pg} / \mathrm{ml})}{\text { Trasylol }}$ & $\frac{- \text { Trasylol }}{+ \text { Trasylol }} \times 100 \%$ \\
\hline 11 & $114 \pm 26$ & $133 \pm 16$ & $117 \pm 30$ & $120 \pm 10$ & $123 \pm 2$ & $103 \pm 9$ \\
\hline 12 & $86 \pm 4$ & $93 \pm 3$ & $108 \pm 6$ & $100 \pm 4$ & $105 \pm 7$ & $105 \pm 8$ \\
\hline 13 & $99 \pm 10$ & $87 \pm 6$ & $88 \pm 11$ & $115 \pm 11$ & $111 \pm 6$ & $97 \pm 11$ \\
\hline 14 & $60 \pm 7$ & $54 \pm 5$ & $90 \pm 13$ & $63 \pm 5$ & $58 \pm 8$ & $92 \pm 15$ \\
\hline 15 & $84 \pm 1$ & $93 \pm 3$ & $111 \pm 4$ & $92 \pm 5$ & $98 \pm 1$ & $107 \pm 6$ \\
\hline 16 & $124 \pm 16$ & $139 \pm 5$ & $112 \pm 15$ & $156 \pm 3$ & $151 \pm 5$ & $97 \pm 4$ \\
\hline 17 & $114 \pm 3$ & $100 \pm 12$ & $88 \pm 11$ & $101 \pm 1$ & $118 \pm 7$ & $117 \pm 7$ \\
\hline 18 & $97 \pm 3$ & $90 \pm 5$ & $93 \pm 6$ & $96 \pm 5$ & $96 \pm 1$ & $100 \pm 5$ \\
\hline 19 & $111 \pm 21$ & $109 \pm 13$ & $98 \pm 22$ & $105 \pm 5$ & $129 \pm 23$ & $123 \pm 23$ \\
\hline \multirow[t]{2}{*}{20} & $74 \pm 11$ & $86 \pm 8$ & $116 \pm 20$ & $86 \pm 1$ & $100 \pm 2$ & $116 \pm 3$ \\
\hline & $96 \pm 20$ & $98 \pm 24$ & & $103 \pm 24$ & $109 \pm 25$ & \\
\hline
\end{tabular}

without added Trasylol. Part of it was centrifuged immediately and stored at $-20^{\circ} \mathrm{C}$, while the rest was left for various time periods at room temperature (tubes without Trasylol) or at $4{ }^{\circ} \mathrm{C}$ (Trasylol-containing tubes) before centrifugation. After 6 days storage at $-20^{\circ} \mathrm{C}$ the immunoreactivity was measured. The samples which were processed as quickly as possible with or without added Trasylol contained, respectively, $124 \pm 12(n=3) \mathrm{pg} / \mathrm{ml}$ and $118 \pm 6(n=3)$ $\mathrm{pg} / \mathrm{ml}$ IRG. The sample without Trasylol which was left at room temperature for 7 hours showed immunoreactivity of $123 \pm 3(\mathrm{n}=3) \mathrm{pg} / \mathrm{ml}$, as compared to $128 \pm 5(\mathrm{n}=3) \mathrm{pg} / \mathrm{ml}$ for its Trasylol-containing control kept on ice for the same time period.

\section{K-immunoreactivity After Gel Chromatography of Plasma}

Plasma IRG assayed with antiserum $30 \mathrm{~K}$, is heterogenous [8]. We therefore investigated whether handling and storage without Trasylol would affect the chromatographic characteristics of total IRG activity.

Blood was collected, both from three healthy persons and three patients with chronic renal failure, and processed and stored at $-20^{\circ} \mathrm{C}$ with and without Trasylol. After nine months plasma from normal persons was assayed with $30 \mathrm{~K}$ and subjected to gel chromatography. Total $30 \mathrm{~K}$-immunoreactivity in plasma 21 was $170 \pm 8 \mathrm{pg} / \mathrm{ml}(\mathrm{n}=3, \pm \mathrm{SD})$ for the Trasylol-containing sample and $180 \pm 10 \mathrm{pg} / \mathrm{ml}$ for the Trasylol-free sample. The recovery values on the column were $115 \%$ and $107 \%$, respectively. Likewise the activities in plasma 22 were, respectively,
$325 \pm 18 \mathrm{pg} / \mathrm{ml}$ (recovery $96 \%$ ) and $310 \pm 11 \mathrm{pg} / \mathrm{ml}$ (recovery $100 \%$ ) and in plasma $2375 \pm 8 \mathrm{pg} / \mathrm{ml}$ (recovery $110 \%$ ) and $92 \pm 12 \mathrm{pg} / \mathrm{ml}$ (recovery $93 \%$ ). Figure 1 gives the $30 \mathrm{~K}$-immunoreactivity in the fractions obtained after gel chromatography. The drawn lines, linking the dots $(\bullet)$, represent the elution profiles of the plasma samples which were processed at $4{ }^{\circ} \mathrm{C}$ in the presence of Trasylol. Clearly a line drawn through the stars (*), representing the elution pattern of the Trasylol-free plasmas, would not be significantly different. A similar result was obtained with plasma collected from patients with chronic renal failure (Fig. 2). Total 30K-immunoreactivity in plasma 24 , measured on the same day as the gel chromatography was performed, was $800 \pm 44 \mathrm{pg} / \mathrm{ml}$ (recovery on column $95 \%$ ) for the Trasylol-containing sample and $768 \pm 64 \mathrm{pg} / \mathrm{ml}$ (recovery $90 \%$ ) for the sample without added Trasylol. For plasma 25 these values were $496 \pm 18 \mathrm{pg} / \mathrm{ml}$ (recovery $107 \%$ ) and $515 \pm 19 \mathrm{pg} / \mathrm{ml}$ (recovery $124 \%$ ), respectively, and for plasma $26544 \pm 40 \mathrm{pg}$ / $\mathrm{ml}$ (recovery $99 \%$ ) and $576 \pm 62 \mathrm{pg} / \mathrm{ml}$ (recovery $85 \%$ ). Again, no significantly different pattern appears to emerge, whether samples were handled at $4^{\circ}$ in the presence of Trasylol or at room temperature without added Trasylol.

\section{Discussion}

Incubation of iodinated glucagon with human plasma results in damage to the tracer. Therefore, in a radioimmunoassay for plasma glucagon the tracer needs to be protected by a protease inhibitor, for example Trasylol $[1,4,5]$. 


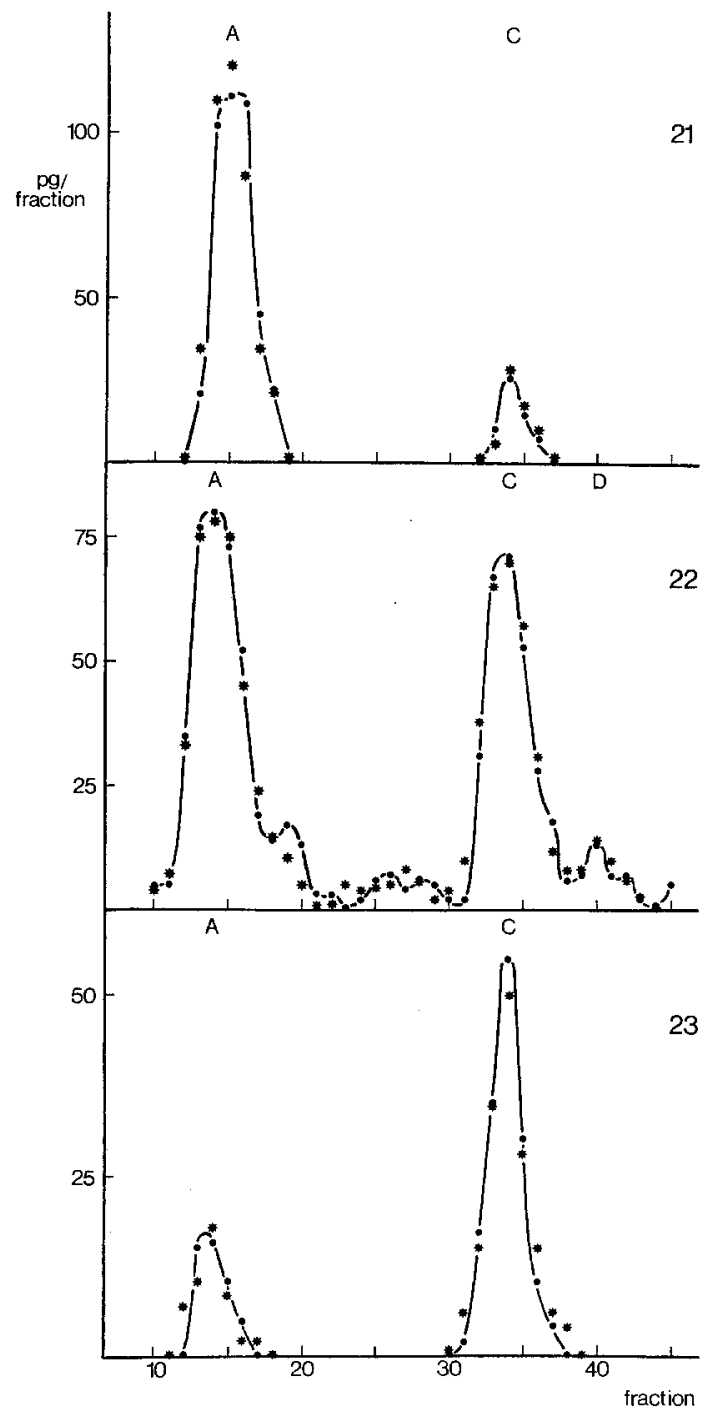

Fig. 1. 30K-immunoreactivity in fractions obtained after gel chromatography of normal human plasma processed in the presence or absence of Trasylol. Blood was collected from three healthy volunteers and each sample was divided into two tubes. Tube 1, containing Trasylol, was kept at $4{ }^{\circ} \mathrm{C}$ for $2 \mathrm{~h}$. Tube 2, without Trasylol, was left at room temperature for $8 \mathrm{~h}$. After centrifugation plasma was stored at $-20^{\circ} \mathrm{C}$ for 9 months and subsequently subjected to gel chromatography on Ultrogel AcA54. Results are expressed as pg immunoreactivity per fraction, both for plasma processed with (•) and without (*) Trasylol. The line is drawn through the dots $(\bullet)$, thus representing the profile of the Trasylol-containing plasma. Peak A represents material with MW $>70.000$, peak $\mathrm{C}$ the MW 3500 component, while peak D consists of material with an approximate MW of 2000

The susceptibility of endogenous IRG to proteolytic attack seems less clear. Both Heding [5] and Nonaka and Foa [6] have reported that addition of Trasylol to blood samples is necessary in order to prevent loss of immunoreactivity. However, Eisentraut et al. [1] and Hazzard et al. [4] both concluded

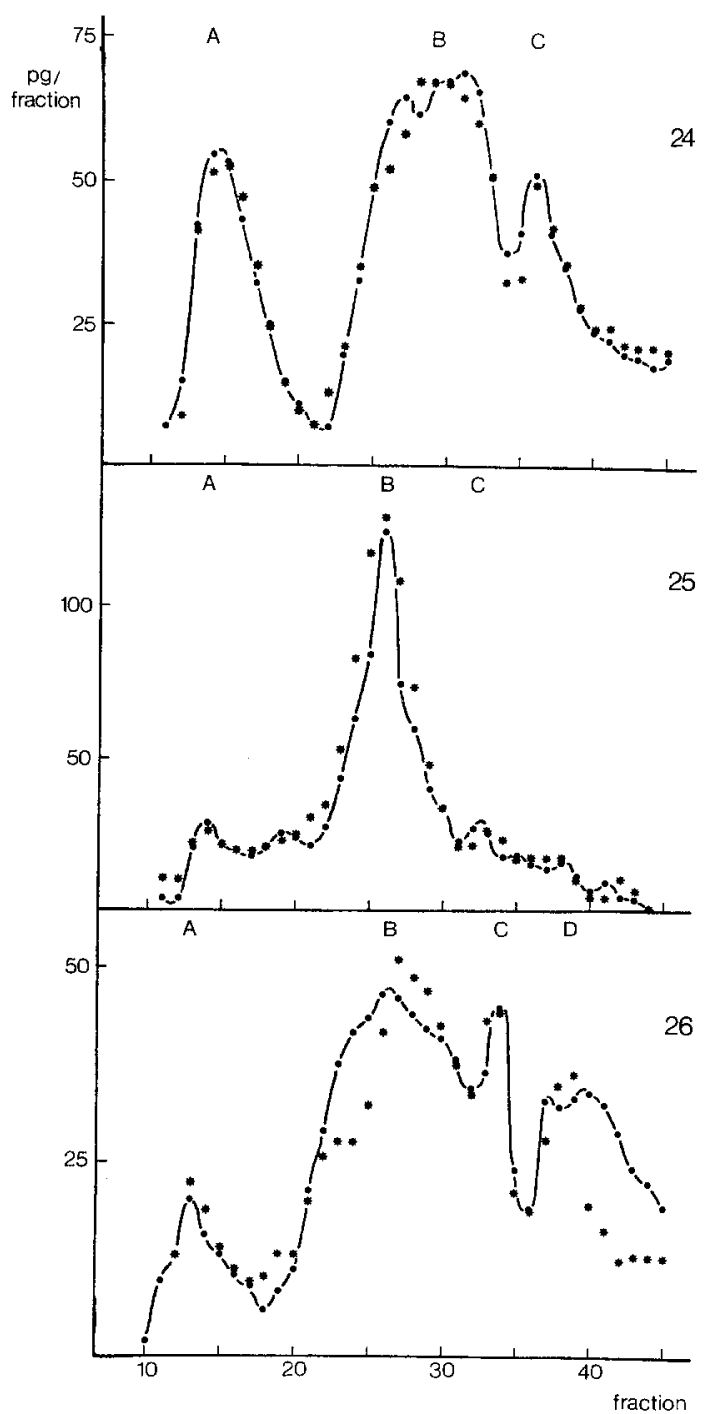

Fig. 2. 30K-immunoreactivity in fractions obtained after gel chromatography of plasma from patients with chronic renal failure, processed in the presence or absence of Trasylol. Blood was collected from three patients with chronic renal failure and each sample was divided into two tubes. Tube 1, containing Trasylol, was kept at $4{ }^{\circ} \mathrm{C}$ for $2 \mathrm{~h}$. Tube 2, without Trasylol, was left at room temperature for $8 \mathrm{~h}$. After centrifugation plasma was stored at $-20^{\circ} \mathrm{C}$ for 10 months and subsequently subjected to gel chromatography on Ultrogel AcA54. Results are expressed as pg immunoreactivity per fraction, both for plasma processed with $(\bullet)$ and without (*) Trasylol. The line is drawn through the dots (•), thus representing the profile of the Trasylol-containing plasma. Peak A represents material with $M W>70000$, peak $B$ contains the MW 9000 component, peak C the MW 3500 component, while peak $\mathrm{D}$ consists of material with an approximate MW of 2000

that it is not necessary to collect blood in Trasylolcontaining tubes. Still, Faloona and Unger [7], describing the processing of blood for the assay of plasma IRG with antiserum $30 \mathrm{~K}$, recommend that the samples be collected in tubes kept in a icebath and containing at least $500 \mathrm{U}$ Trasylol $/ \mathrm{ml}$ blood. 
Antiserum $30 \mathrm{~K}$ is widely used throughout the world. The generally accepted procedure for collection and processing of blood samples may prevent some laboratories from carrying out glucagon radioimmunoassays because of the high costs of Trasylol or a lack of a centrifuge which can operate at $4{ }^{\circ} \mathrm{C}$. Also, it is assumed that IRG cannot be measured in plasma samples taken for other purposes where Trasylol is omitted and blood is processed at room temperature.

Our results indicate that it may be possible to assay 30K-immunoreactivity in human blood processed at room temperature without added Trasylol. If blood is collected and processed immediately at $4{ }^{\circ} \mathrm{C}$ in the presence of Trasylol, the IRG level measured after 6 days of storage is not higher than in the samples obtained from the same person at the same time, but deliberately left at room temperature for up to 7 hours in the absence of Trasylol. Also, storage of plasma samples without added Trasylol at $-20{ }^{\circ} \mathrm{C}$ for up to 74 days does not lead to a significant decrease in $30 \mathrm{~K}$-immunoreactivity as compared to the Trasylol-containing controls (Tables 1 and 2). One might suppose that the omission of Trasylol leads to a degradation of native IRG into smaller fragments, which retain immunoreactivity. However, the results from the gel chromatography experiments (Figures 1 and 2) do not support this hypothesis. The $30 \mathrm{~K}$-immunoreactivity of any of three major components of plasma IRG, big plasma glucagon, IRG ${ }^{9000}$ or IRG ${ }^{3500}$, appears significantly affected by handling under Trasylol-free conditions.

To summarise, in none of the human plasma samples investigated, did the processing of blood under, supposedly, glucagononlysis favouring conditions lead to a loss of $30 \mathrm{~K}$-immunoreactivity. It is suggested that the precautions, which are generally accepted as necessary to prevent damage to endogenous glucagon, may in fact be superfluous if samples are to be assayed with antiserum $30 \mathrm{~K}$.
Acknowledgements. The authors wish to thank Mrs. M. M. P. J. Vossen for excellent technical assistance, Dr. J. A. Lutterman for help with obtaining the blood samples and Dr. G. Janes for critically reading the manuscript.

\section{References}

1. Eisentraut AM, Whissen N, Unger RH (1968) Incubation damage in the radioimmunoassay for human plasma glucagon and its prevention with Trasylol. Am J Med Sci 255: 137-142

2. Ensinck JW, Shepard C, Dudl RJ, Williams RH (1972) Use of benzamidine as a proteolytic inhibitor in the radioimmunoassay of glucagon in plasma. J Clin Endocrinol Metab 35: 463-467

3. Mirsky IA, Perisutti G, Davis NC (1959) The destruction of glucagon by the blood plasma from various species. Endocrinology 64: 992-1001

4. Hazzard WR, Crockford PM, Buchanan KD, Vance JE, Chen R, Williams R H (1968) A double antibody immunoassay for glucagon. Diabetes 17: 179-186

5. Heding LG (1971) Radioimmunological determination of pancreatic and gut glucagon in plasma. Diabetologia 7: 10-19

6. Nonaka K, Foa PP (1969) A simplified glucagon immunoassay and its use in a study of incubated pancreatic islets. Proc Soc Exp Biol Med 130: 330-336

7. Faloona GF, Unger RH (1974) Glucagon. In: Jaffe BM, Behrman HR (eds) Methods of hormone radioimmunoassay. Academic Press, New York, p 317-330

8. Valverde I, Villanueva ML, Lozano I, Marco J (1974) Presence of glucagon immunoreactivity in the globulin fraction of human plasma ("big plasma glucagon"). J Clin Endocrinol Metab 39: 1090-1098

Received: 2 June 1980 ,

and in revised form: 5 December 1980

Dr. T. Hendriks

Department of Experimental and Chemical Endocrinology

University of Nijmegen

Geert Grooteplein Noord 21

$6525 \mathrm{EX}$ Nijmegen

The Netherlands 